\title{
Tracheal Intubation
}

National Cancer Institute

\section{Source}

National Cancer Institute. Tracheal Intubation. NCI Thesaurus. Code C116648.

The insertion of a plastic tube through the mouth or nose that extends past the vocal cords and into the trachea for the purpose of oxygenating and ventilating the patient, and to prevent the passage of unwanted material into the lungs. 